Research article

\title{
The dehydration kinetics, physical properties and nutritional content of banana textured by instantaneous controlled pressure drop ${ }^{\dagger}$
}

\author{
Puguh Setyopratomo, ${ }^{1 *}$ Akbarningrum Fatmawati, ${ }^{1}$ Putu Doddy Sutrisna, ${ }^{1}$ Emma Savitri ${ }^{1}$ and Karim Allaf ${ }^{2}$ \\ ${ }^{1}$ Chemical Engineering Department, Engineering Faculty, University of Surabaya, Raya Kalirungkut, Surabaya, Indonesia, 60292 \\ ${ }^{2}$ Laboratory Mastering Technology for Agro-Industry, University of La Rochelle, La Rochelle, France
}

Received 20 January 2011; Revised 1 July 2011; Accepted 4 July 2011

\begin{abstract}
Texturing by instantaneous controlled pressure drop is used to modify texture of banana slices, which was aimed to improve properties of banana flour. Texturing step is inserted between initial and final hot air drying steps. The aim of this research is to investigate the effect of the texturing on the dehydration kinetic, physical properties and nutritional characteristic of banana. Some impacts of the texturing have been identified. The results of this work showed that the texturing increased the effective moisture diffusivity and the water holding capacity, but reduced the oil holding capacity of banana. This work also showed that the banana texturing inhibited the transformation of banana starch to reduction of sugar that might be attributable to enzyme deactivation during the texturing process. (C) 2011 Curtin University of Technology and John Wiley \& Sons, Ltd.
\end{abstract}

KEYWORDS: banana; effective diffusivity; oil holding capacity; water holding capacity; nutrition

\section{INTRODUCTION}

Banana flour is produced from fresh banana fruit through dehydration (drying) process. Basically, the dehydration process is the removal of water from the banana fruit to a certain level at which microbial spoilage is avoided. In Indonesia, the dehydration method mostly used to produce banana flour is sun drying. Because this method needs much time exposure, significant deterioration will occur during the drying process, which can result in very low quality of the banana flour product. In this work, a new process of texturing by instantaneous control pressure drop, called the déetente instantanée contrôlée (DIC), was introduced between initial and final hot air drying. The purpose of the texturing step is to modify the material texture to improve the product quality including the product physical properties.

The DIC technology was initially developed by Allaf et al., since 1988, in the University of La Rochelle, France. ${ }^{[1-4]}$ It applied instantaneous pressure drop to modify the texture of the material and intensify functional behaviour. The DIC treatment usually starts by creating a vacuum condition, followed by injecting

*Correspondence to: Puguh Setyopratomo, Chemical Engineering Department, Surabaya University, Jl. Raya Kalirungkut, Surabaya 60292, Indonesia. E-mail: puguh_sptm@yahoo.com

${ }^{\dagger}$ Revised from paper presented at the Chemeca 2010, 26-29 September, Adelaide, Australia. steam to the material, which keeps contact for several seconds, and then proceeds to apply sudden pressure drop toward vacuum (about $5 \mathrm{kPa}$ with a rate higher than $0.5 \mathrm{MPa} / \mathrm{s}$ ). This treatment is also categorised as a high temperature short time (HTST ) process. By suddenly dropping pressure, rapid auto vaporisation of the moisture from the material will occur, the material will swell and lead to texture change, which results in higher porosity. ${ }^{[5]}$ It increases the material porosity as well as the specific surface area and reduces the diffusion resistance of moisture during the final dehydration step. Such a thermo-mechanical treatment also induces microbiological decontamination. ${ }^{[6]}$

This research was aimed to apply the DIC technology in the production of banana flour. The variation of the process variables, i.e. steam pressure/temperature and time of treatment in DIC reactor, will be studied in accordance with the kinetics of dehydration, the physical properties, which include water and oil holding capacity and the nutritional characteristics.

\section{MATERIALS AND METHODS}

\section{Raw material}

Freshly harvested banana fruit (Musa sp) were purchased locally and used in all experiments. After peeling, the banana fruit were cut into pieces of $16 \times 16 \times 2 \mathrm{~mm}^{3}$. 


\section{Dehydration method}

The banana pieces were subjected to a stream of hot air at $50^{\circ} \mathrm{C}$ in a convective hot air dryer (Memmert UFE 600 , Schwabach, Germany). The banana pieces were dried until the residual moisture content of about $20 \%$ (wet basis). This condition was maintained before DIC treatment. The same hot air dryer and conditions were used for initial as well as for final dehydration.

\section{The DIC reactor}

The DIC reactor is shown schematically in Fig. 1. The reactor consisted of four major components, i.e. (a) the processing vessel $\left(1.5 \times 10^{-3} \mathrm{~m}^{3}\right.$ volume $)$, where samples were placed and treated, (b) the vacuum system, which consisted mainly of a vacuum tank with a volume 60 -fold greater than the processing vessel, (c) the adequate vacuum pump, and (d) the pressuredropping system, which is a pneumatic valve, separated by the processing vessel from the vacuum tank and could be operated after a high steam pressure treatment, and if required, before the injection of steam to establish an initial vacuum in the processing vessel.

\section{The experimental procedure}

The general experimental protocol is detailed in Fig. 2. After preparing the raw food material, an initial partial dehydration, was carried out. This pre-treatment is required before the DIC processing. The food material was then treated in the processing vessel in which a vacuum of $5 \mathrm{kPa}$ was established by a brief connection to the vacuum tank [Fig. 3(b)]. The initial vacuum treatment facilitated the diffusion of steam into the sample. Consequently, the time necessary for the

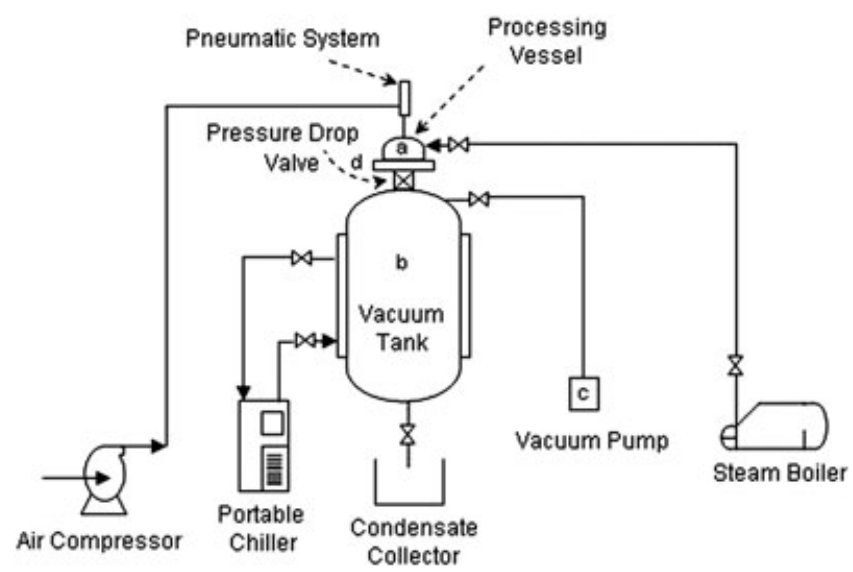

Figure 1. Schematic diagram of the DIC reactor: (a) treatment vessel with heating jacket; (b) vacuum tank with cooling liquid jacket; (c) vacuum pump; (d) instant pressure-drop valve. sample to reach the steam temperature was reduced. Saturated steam was subsequently introduced into the processing vessel at a fixed pressure level [Fig. 3(c)] and maintained for a predetermined time [Fig. 3(d)]. This step was followed by a sudden pressure drop [Fig. 3(e)]. The rapid pressure drop inside the processing vessel induced a rapid cooling of the sample, which passed in less than $1 \mathrm{~s}$ from $100-144{ }^{\circ} \mathrm{C}$ (depending on the steam pressure conditions) to about $30^{\circ} \mathrm{C}$. The treatment was ended by contacting the sample to the atmospheric pressure [Fig. 3(f and $\mathrm{g})$ ]. As the atmospheric air injection occurred under vacuum condition, the air expansion decreased the treated food temperature further.

The equilibrium after the pressure drop depended on the operating conditions: the higher the steam pressure level, the higher the equilibrium pressure. The steam generated by flash vaporisation after the decompression produced microtexturing, which was closely linked to a complex process of micro-alveolation. This process depended on the difference in temperature between the two thermodynamic equilibrium states, before and after decompression. After treatment, the sample was air-dried at $50{ }^{\circ} \mathrm{C}$ in convective hot air dryer to around $7 \%$ (w. b.) moisture content. The dried banana pieces were then ground using a commercial grinder (Philips Grinder, Philips, Amsterdam, The Netherlands) to pass a 200 mesh sieve and stored at $25^{\circ} \mathrm{C}$ in sealed plastic containers prior to further analyses.

\section{FUNDAMENTALS}

There are four transfer mechanisms, which usually intervene during the drying process; they are as follows: 1) Heat transfer from outside towards the product surface; the energy can be generally brought by contact, convection or radiation, 2) Heat transfer within the product; the energy is transmitted by conduction, 3) Water transfer within the product; it is carried out either in liquid (by various process including capillarity and molecular diffusivity; the driving force is the gradient of water content) and/or vapour phase (the driving force is the gradient of the partial pressure of vapour), 4) Vapour transport from the surface towards outside. Energy exchange to the product surface result in constant rate drying period and proceed in very short time. ${ }^{[7]}$ Then, especially for biomaterials, during almost overall drying process, the water transfer takes place within the product that results in falling rate of drying.

By assuming that external heat and mass transfers do not limit the overall rate operation, and that there are adequate air flow temperature and velocity, only internal transfers are considered as controlling the processes. Mounir and Allaf assumed that, when mass transfer is much slower than conductive heat transfer within the product, the drying kinetics is controlled 


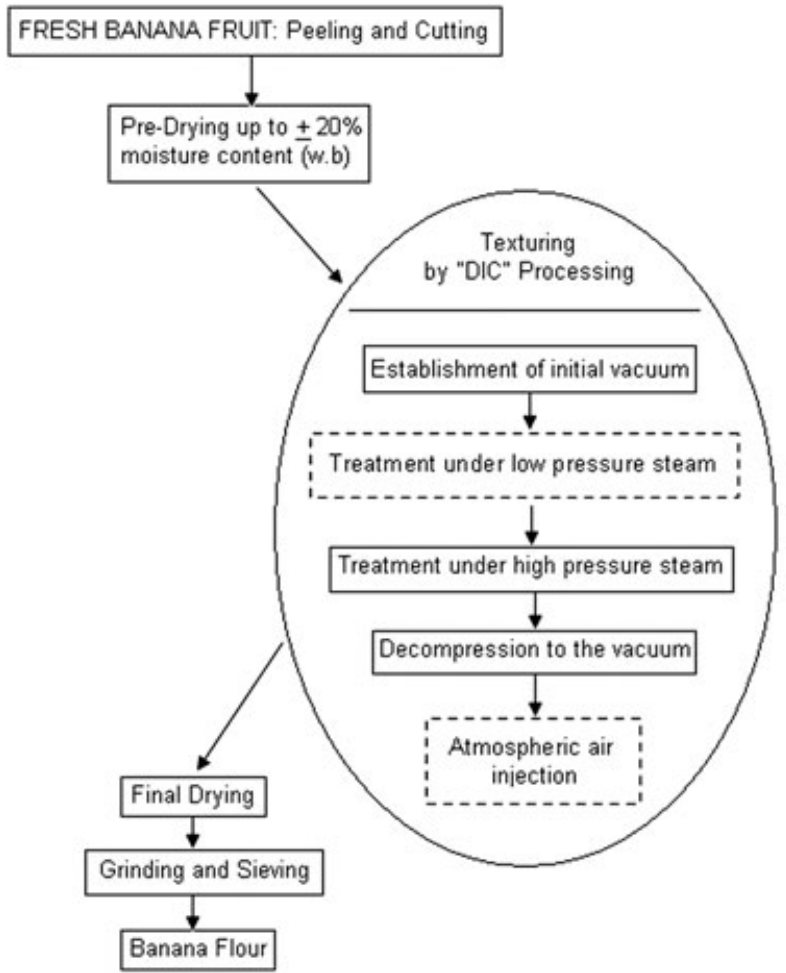

Note:

Systematic Step

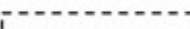
Possible Step

Figure 2. Schematic diagram of global processing.

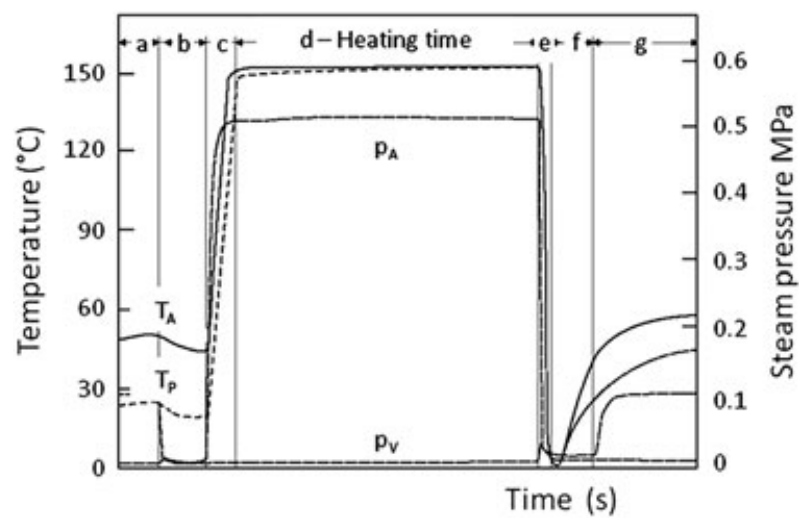

Figure 3. DIC temperature and pressure history: $P_{\mathbf{A}}$ and $T_{\mathbf{A}}$ are the steam pressure and temperature respectively in the processing vessel, $P_{\mathbf{V}}$ the vacuum tank pressure, $T_{\mathbf{P}}$ temperature of product: (a) sample at atmospheric pressure; (b) initial vacuum; (c) saturated steam injection to reach the selected pressure; (d) constant temperature corresponding to saturated steam pressure; (e) abrupt pressure drop towards vacuum; ( $f$ and $g$ ) releasing to the atmospheric pressure.

by mass transport of water within the granule; this is the case of numerous biopolymers. ${ }^{[8]}$ The process is then described by a first stage of superficial interaction followed by a diffusion Fick's-type law within the material; Allaf's formulation is generally used: ${ }^{[9]}$

$$
\frac{\rho_{\mathrm{w}}}{\rho_{\mathrm{m}}}\left(\vec{v}_{\mathrm{w}}-\vec{v}_{\mathrm{m}}\right)=-D_{\text {eff }} \operatorname{grad} \frac{\rho_{\mathrm{w}}}{\rho_{\mathrm{m}}}
$$

where:

$\rho_{w} \quad$ apparent density of water in the material $\left(\mathrm{kg} \mathrm{m}^{-3}\right)$

$\rho_{\boldsymbol{m}}$ apparent density of dry material $\left(\mathrm{kg} \mathrm{m}^{-3}\right)$

$v_{w}$ absolute velocity of water flow within the porous medium $\left(\mathrm{m} \mathrm{s}^{-1}\right)$.

$v_{\boldsymbol{m}}$ absolute velocity of solid medium $\left(\mathrm{m} \mathrm{s}^{-1}\right)$.

$D_{\text {eff }}$ effective diffusivity of water within the solid medium $\left(\mathrm{m}^{2} \mathrm{~s}^{-1}\right)$.

Mounir and Allaf assumed neglecting effects of possible shrinkage, and with the hypothesis of constant effective diffusivity during drying, Fick's second law becomes for 1-D: ${ }^{[7]}$

$$
\frac{\partial \rho_{\mathrm{w}}}{\partial \mathrm{t}}=\left[D_{\mathrm{eff}} \frac{\partial^{2} \rho_{\mathrm{w}}}{\partial L_{\mathrm{o}}^{2}}\right]
$$

Where $\mathrm{L}_{\mathrm{o}}$ is the thickness of the material (m). At the temperature and moisture content ranges studied in the present stage of the research work, drying process was considered as having insignificant impact on the banana structure because of the absence of shrinkage; the effective diffusivity $D_{\text {eff }}$ was assumed to be constant. Different mathematical solutions have been 
proposed for this equation, depending on the initial and boundary conditions; ${ }^{[10]}$ in our study, we can adopt the solution given by Crank, according to the geometry of the solid matrix ${ }^{[11]}$ by expressing the amount $X$ of water in the solid, Eqn (2) becomes:

$$
\mathrm{MR}=\frac{X-X_{\mathrm{e}}}{X_{0}-X_{\mathrm{e}}}=\sum_{i=1}^{\infty} A_{\mathrm{i}} \exp \left(-q_{\mathrm{i}}^{2} t\right)
$$

Where MR is moisture ratio, $X$ is the water content dry basis at $t, X_{\mathrm{e}}$, is the amount of $X$ at equilibrium $(\mathrm{t} \rightarrow \infty)$ and $X_{0}$ the value of $X$ at $\mathrm{t}=0$. For a slab geometry form, Eqn (3) becomes:

$$
\mathrm{MR}=\frac{8}{\pi^{2}} \sum_{n=0}^{\infty} \frac{1}{(2 n+1)^{2}} \exp \left(-\frac{(2 n+1)^{2} \pi^{2} D_{\mathrm{eff}} t}{4 L_{0}^{2}}\right)
$$

Where $D_{\text {eff }}$ is the effective diffusivity $\left(\mathrm{m}^{2} / \mathrm{s}\right)$. For long drying period, Eqn (4) can be further simplified to only the first term of series. ${ }^{[12,13]}$ Thus Eqn (4) could be expressed in linear logarithmic form as follows:

$$
\ln M R=\ln \frac{8}{\pi^{2}}-\frac{\pi^{2} D_{\text {eff }} \mathrm{t}}{4 L_{0}^{2}}
$$

\section{Water and oil-holding capacity determination}

Method proposed by Larrauri was used with slight modification. ${ }^{[14]}$ Five millilitres of distilled water or commercial olive oil were added to $0.2 \mathrm{~g}$ dry sample, which was then incubated at $40^{\circ} \mathrm{C}$ for $1 \mathrm{~h}$. After centrifugation, the liquid phase was separated and the residue was weighed. The water holding capacity (WHC) and the oil holding capacity $(\mathrm{OHC})$ were calculated as the ratio of water or oil weight absorbed in gramme to that of dry sample in gramme.

\section{Determination of nutritional characteristics}

The protein content was determined using Kjeldahl method (AOAC method 988.05). The fat content was analysed according to AOAC method 920.39. The ash and raw fibre content were determined by gravimetric method accoding to AOAC method 942.05, and 962.09, respectively. The Luff-Schoorl method was used to analyse the reduction of sugar content. The calcium, sodium, potassium and magnesium content was analysed using atomic absorption spectrophotometer according to AOAC method 988.35. High performance liquid chromatography analysis was used to determine the concentration of vitamin $\mathrm{C}$, BHA, BHT and TBHQ.

\section{Experimental design and statistical analysis}

Interaction effect betwen the design variables was analysed by response surface methodology (RSM). A twovariable central composite rotable design was used. This design needs at least 13 experiments including four-repetition runs at the centre point. The experiments were run in random to minimise the effects of unexpected variability in the observed responses because of extraneous factors. For each factor, the experimental range and the central point were based on the results of other preliminary experiments. Table 1 lists the independent variables, their symbol, the coded and real factor level. The objective was to observe the influence of the process variables, i.e. steam pressure/ temperature and time of treatment in DIC reactor on the dependent responses, which consisted of banana flour physical properties, including WHC and OHC. The processing pressure $\left(\xi_{1}\right)$ and the treatment time $\left(\xi_{2}\right)$ were set as the design variables. The dependent variables (referred to as responses), $\eta$, which were experimentally measured, were assumed to be affected by the two independent variables $\xi_{i}$ and was formulated as follows:

$$
\eta=f\left(\xi_{1}, \xi_{2}\right)
$$

The obtained experimental data were analysed by RSM to fit to the following second-order polynomial model:

$$
\eta=\beta_{0}+\sum_{i=1}^{2} \beta_{i} x_{i}+\sum_{i=1}^{2} \beta_{i i} x_{i}^{2}+\beta_{12} x_{12}
$$

where $\beta_{\mathrm{o}}, \beta_{i}, \beta_{i i}$ and $\beta_{12}$ are regression coefficients and

Table 1. Experiment runs expressed in coded and real values.

\begin{tabular}{lcccccc}
\hline & & \multicolumn{2}{c}{$\begin{array}{c}\text { Saturated steam } \\
\text { pressure }\end{array}$} & & \multicolumn{2}{c}{$\begin{array}{c}\text { High temperature } \\
\text { processing time }\end{array}$} \\
\cline { 5 - 6 } No & & $\begin{array}{c}\text { Coded } \\
\text { level }\end{array}$ & $\begin{array}{c}\text { Real values } \\
(\mathrm{MPa})\end{array}$ & & $\begin{array}{c}\text { Coded } \\
\text { level }\end{array}$ & $\begin{array}{c}\text { Real } \\
\text { values (s) }\end{array}$ \\
\hline 1 & 0 & 0.4 & & $-\alpha$ & 12.3 \\
2 & 0 & 0.40 & & 0 & 30 \\
3 & $-\alpha$ & 0.26 & & 0 & 30 \\
4 & 0 & 0.40 & & 0 & 30 \\
5 & 0 & 0.40 & & + & 47.7 \\
6 & 0 & 0.40 & & 0 & 30 \\
7 & 0 & 0.40 & & 0 & 30 \\
8 & 0 & 0.40 & & 0 & 30 \\
9 & +1 & 0.50 & & +1 & 42.5 \\
10 & + & 0.54 & & 0 & 30 \\
11 & -1 & 0.30 & & +1 & 42.5 \\
12 & -1 & 0.30 & & -1 & 17.5 \\
13 & +1 & 0.50 & & -1 & 17.5 \\
& & & & &
\end{tabular}

$\alpha=\sqrt[4]{2^{N}}, N$ is the number of independent variables. In the present case: $N=2$ and $\alpha=1.4142$ 
$x_{i}$ are the coded variables linearly related to $\xi_{i}$. The coding of $\xi_{i}$ into $x_{i}$ is expressed by the following equation:

$$
x_{i}=2\left(\xi_{i}-\xi_{i}^{*}\right) / d_{i}
$$

where $\xi_{i}=$ actual value in original units; $\xi_{i}^{*}$ mean of high and low levels of $\xi_{i}$; and $d_{i}=$ difference between the low and high levels of $\xi_{i}$.

\section{RESULTS AND DISCUSSION}

\section{The texture change}

To observed texture change during DIC treatment, an observation was conducted on the surface of the dried banana slices by using a scanning electron microscope, and the results were presented in Figs. 4 and 5. Those scanning electron microscope pictures show formation of micropores within the product. The instantaneous pressure drop and rapid autovaporation of moisture surely became the factor that promotes the formation of such micropores.

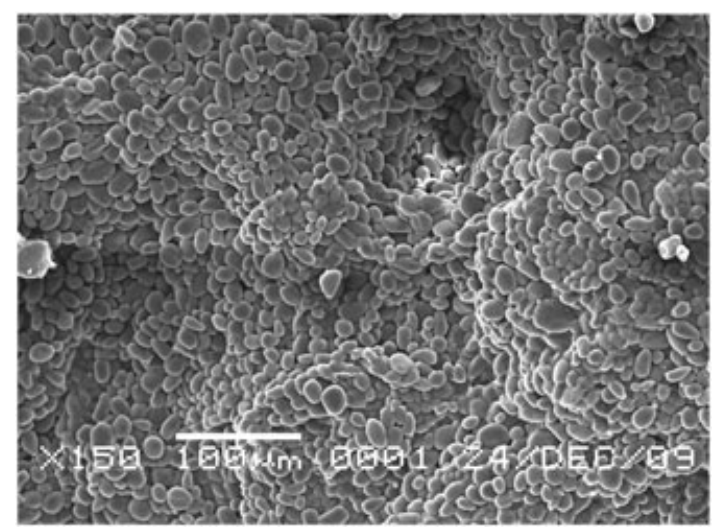

Figure 4. Dried banana before DIC treatment.

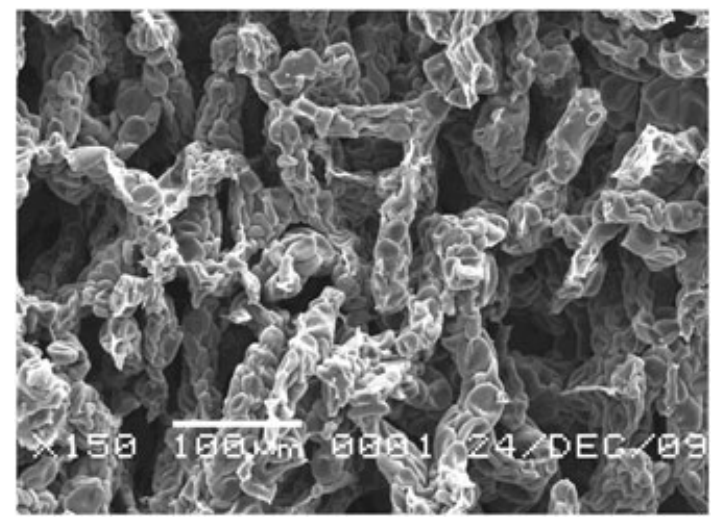

Figure 5. Dried banana after DIC treatment.

\section{Moisture effective diffusivity ( $\left.D_{\text {eff }}\right)$}

The initial moisture contents of the banana obtained from the several experiments run were in the range of $60-62 \%$ (w. b.). The final moisture contents were in the range of 6-8\% (w. b.). The observed profile of the moisture content change, that is expressed as moisture ratio (MR) change, is presented in Fig. 6. It showed that the experimental data lied on curvature profile, which indicated that falling rate drying mechanism had occurred during the whole drying period. In such case, water diffusion mechanism would control the process. To investigate the impact of DIC texturing on the drying kinetics, the main parameter had been the water diffusivity within the material. Taking the prerequisite assumption and setting material thickness $2 \mathrm{~mm}$ as $\mathrm{L}_{\mathrm{o}}$, then the effective diffusivity ( $\left.D_{\text {eff }}\right)$ was calculated using Eqn (5). The results showed that the DIC treatment increased the water effective diffusivity.

The reference $D_{\text {eff }}$ obtained with non-DIC-treated drying (drying without inserting DIC treatment) had been $8.11 \times 10^{-10} \mathrm{~m}^{2} / \mathrm{s}$, whereas the $D_{\text {eff }}$ values obtained from DIC-treated drying was higher, which was $10.01 \times 10^{-10} \mathrm{~m}^{2} / \mathrm{s}$. It indicated that the change in banana physical properties, such as capillary and molecular diffusivity, had occurred during texturing by DIC treatment.

This hypothesis was enhanced by the fact that observation using scanning electron microscope, which was taken on the banana slice surface, show formation of micropores within the product. The formation of micropores led to faster moisture diffusion within the product. The higher $D_{\text {eff }}$ value attributable to the texture change is one among other advantages of DIC treatment application, especially for biomaterial products.

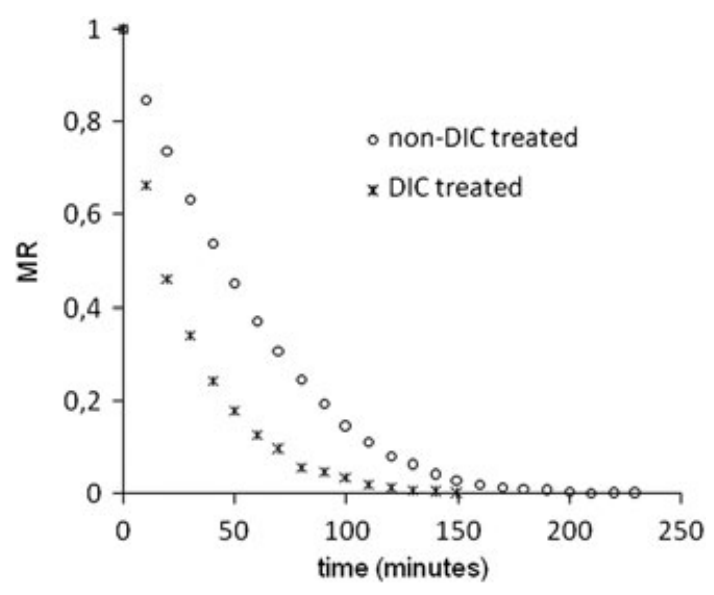

Figure 6. The profile of the moisture content change expressed as moisture ratio (MR). 


\section{The water and the oil holding capacity}

The WHC and the OHC are the physical properties that indicate the capacity to hold water and oil, respectively. Both these physical properties to have influent on the further processing of flour or powder food products such as blending to produce a certain final food product. Thus, appropriate WHC or OHC of food raw material becomes an important property. In this work, the effect of DIC treatment on WHC and OHC of the banana flour was studied.

Surface and contour plots for WHC were presented in Figs 7 and 8, whereas those for OHC were presented in Figs 9 and 10. It was found that the WHC of more than $7 \mathrm{~g}$ water/g was achieved by DIC treatment at a relatively high steam pressure (more than $4.5 \times 10^{-5} \mathrm{~Pa}$ ) for DIC treatment time between $30-45 \mathrm{~s}$. It was also found that the WHC will be very low, below $3 \mathrm{~g}$ water/g, at the level of steam pressure less than $3.0 \times 10^{-5} \mathrm{~Pa}$, and DIC treatment time less than $15 \mathrm{~s}$. In regard to $\mathrm{OHC}$, OHC more than $1 \mathrm{~g}$ oil/g was achieved by DIC treatment at relatively low steam pressure (less than $4.0 \times 10^{-5} \mathrm{~Pa}$ ) for DIC treatment time less than $25 \mathrm{~s}$. The $\mathrm{OHC}$ will be very low, below

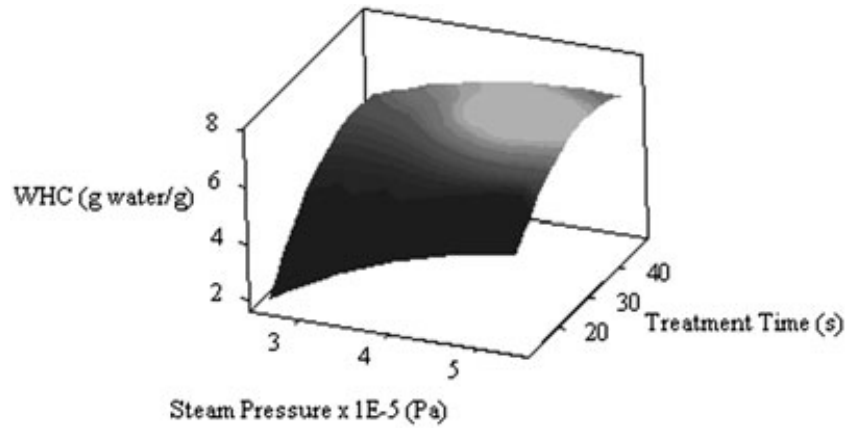

Figure 7. Surface plot of the water holding capacity.

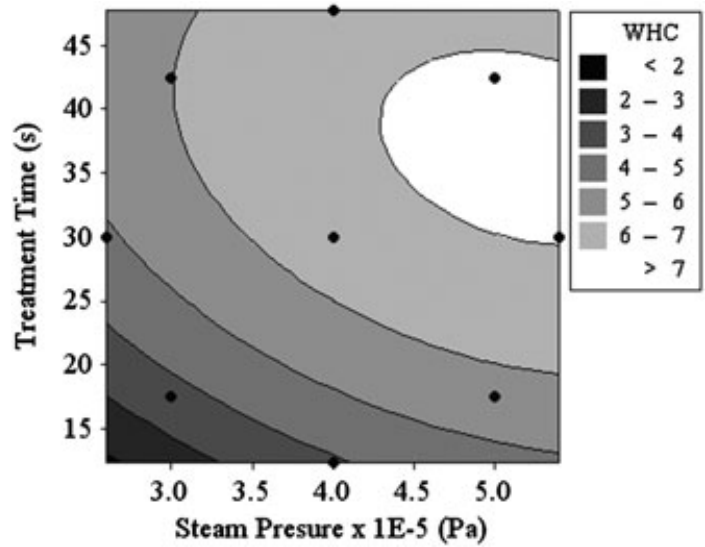

Figure 8. Contour plot of the water holding capacity.
$0.6 \mathrm{~g} \mathrm{oil} / \mathrm{g}$, at the level of steam pressure more than $5.0 \times 10^{-5} \mathrm{~Pa}$ and DIC treatment time more than $35 \mathrm{~s}$.

It was also found that texturing by DIC resulted in the increase of WHC from $2.0 \mathrm{~g}$ water/g dry banana (drying without DIC treatment) to 3.3-7.8 g water/g dry banana. On the other hand, texturing by DIC resulted in the decrease of the $\mathrm{OHC}$ from $1.3 \mathrm{~g}$ oil/g dry banana (drying without DIC treatment) to $0.6-1.1 \mathrm{~g}$ oil $/ \mathrm{g}$ dry banana. The effect of pressure and treatment time on the WHC and OHC might be correlated with the change in its nutritional composition especially protein, thus reducing sugar and raw fibre content.

The trend result for the WHC indicated that the texture change resulted from the application of instantaneous pressure, and temperature drop has significantly changed the material structure. The formation of micropores during this treatment might have a correlation with the increasing specific surface of the material, which might increase the WHC. Meanwhile, the decreasing $\mathrm{OHC}$ might be correlated with the decrease of the fat, protein and sugar content after the material exposure to high temperature during the DIC treatment as shown in Table 2. The decreasing fat, protein and sugar content might correlate with the decreasing hydrophobic character of the material.

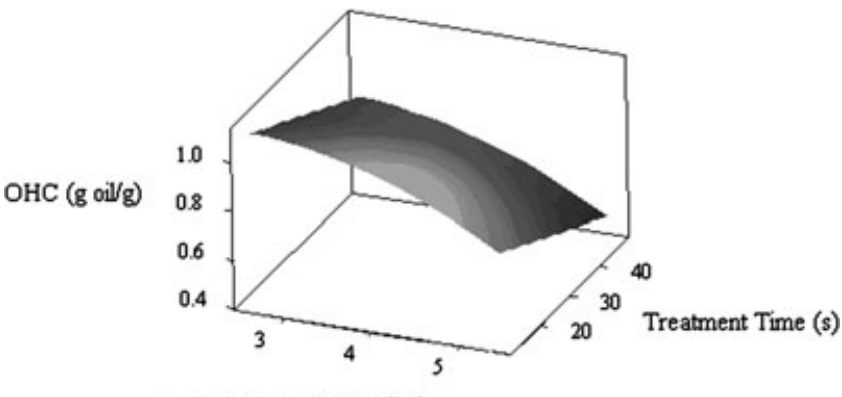

Steam Pressurex1E-5 (Pa)

Figure 9. Surface plot of the oil holding capacity.

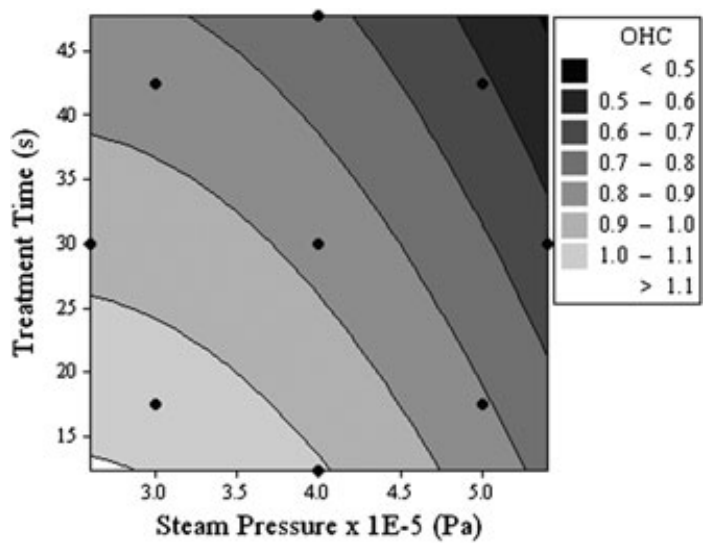

Figure 10. Contour plot of the oil holding capacity. 
Table 2. Nutritional characteristics of the banana flour among different processes.

\begin{tabular}{lrrrr}
\hline & & \multicolumn{3}{c}{ Process } \\
\cline { 3 - 5 } Parameter & Unit & $\begin{array}{c}\text { Sun } \\
\text { dried }\end{array}$ & $\begin{array}{c}\text { Non-DIC } \\
\text { treated }\end{array}$ & $\begin{array}{c}\text { DIC } \\
\text { treated }\end{array}$ \\
\hline Protein & $\%$ & 3.01 & 3.02 & 2.76 \\
Fat & $\%$ & 0.28 & 0.41 & 0.34 \\
Ash & $\%$ & 2.72 & 2.62 & 2.74 \\
Raw fibre & $\%$ & 0.85 & 0.65 & 1.40 \\
Carbohydrate & $\%$ & 86.27 & 87.20 & 86.55 \\
Calorific & $\mathrm{kcal} /$ & 359.64 & 364.57 & 360.30 \\
value & $100 \mathrm{~g}$ & & & \\
Reduction of & $\%$ & 5.86 & 6.22 & 1.55 \\
Sugar & & & & \\
Phosphorus & $\%$ & 0.09 & 0.10 & 0.08 \\
Calcium & $\%$ & 0.03 & 0.04 & 0.06 \\
Sodium & $\%$ & 0.02 & 0.02 & 0.02 \\
Potassium & $\%$ & 0.99 & 0.92 & 1.0 \\
Magnesium & $\%$ & 0.04 & 0.04 & 0.04 \\
Vitamin C & ppm & $<0.5$ & $<0.5$ & $<0.5$ \\
BHA & ppm & $<0.5$ & $<0.5$ & $<0.5$ \\
BHT & ppm & $<0.5$ & $<0.5$ & $<0.5$ \\
TBHQ & ppm & $<0.5$ & $<0.5$ & $<0.5$ \\
& & & & \\
\hline
\end{tabular}

\section{Nutritional characteristics}

The nutritional characteristic of sun dried, non-DICtreated and DIC-treated banana are shown in Table 2. Sun-dried banana was obtained by exposing the banana slices to the sun light outdoor. It needed around 3 days to attain the moisture content of less than $8 \%$ (w. b.). Compared to the sun-dried and non-DIC-treated banana, the protein content of DIC-treated banana was lower. Some portion of the protein content of banana might decompose at the high temperature treatment of DIC. The DIC-treated banana also exhibited the lowest reduction in sugar content compared to the other two treatments. This showed that the indigenous enzyme responsible for the hydrolysis of banana starch into the reduction of sugar might be deactivated or decomposed during DIC heat treatment. This was also supported by the fact that the lost protein content might include some indigenous enzymes. The other nutritional contents and caloric values of DIC-treated banana are not significantly different from the two other treatment methods. Compared with the sun drying and the non-DIC treatment, the lower fractions of protein and the reduction of sugar in the DIC-treated banana might also be correlated with the higher fraction of its raw fibre.

\section{CONCLUSION}

The impact of the texturing by instantaneous controlled pressure drop on the effective moisture diffusivity, the
WHC and the $\mathrm{OHC}$, and the nutritional characteristics of banana have been investigated. The texturing by instant controlled pressure drop has increased the effective moisture diffusivity, increased the WHC and reduced the OHC. It has been found that the banana texturing by DIC inhibited the transformation of banana starch to the reduction of sugar that might be attributable to enzyme deactivation during the heat treatment process.

\section{Acknowledgement}

The authors wish to thank THE ABCAR-DIC PROCESS SAS, La Rochelle France for providing a set of DIC equipment. Financial support from the Expertise Area Development Program Project-University of Surabaya is gratefully acknowledged.

\section{REFERENCES}

[1] K. Allaf, P. Vidal. Feasibility study of a new process of drying/swelling by instantaneous decompression toward vacuum of in-pieces vegetables in view of a rapid rehydration. Gradient Activity Plotting, University of Technology of Compiegne UTC $\mathrm{N}^{\circ} \mathrm{CR} / 89 / 103$, industrial SILVA-LAON partner, 1989.

[2] K. Allaf, N. Louka, J.M. Bouvier, F. Parent, M. Forget. Method for processing materials to change their texture apparatus, therefore, and resulting materials. 01/05/1999, Document Type and Number: United States Patent 5855941. French Patent No. 93 09720. International extension No. PCT/FR94/00975, 1993.

[3] M. Al-Haddad, S. Mounir, V. Sobolik, K. Allaf. Proceedings of European Drying Conference, Biarritz France, AFSIA, 2007.

[4] M. Al-Haddad, S. Mounir, V. Sobolik, K. Allaf. Int. J. Food Eng., 2008; 4(6), art. 9. DOI: 10.2202/1556-3758.1491

[5] K. Allaf. Proceedings of the 1st Franco-Lebanese Symposium on technologies and Studies on Process Engineering and Biochemistry, Lebanese University, Beirut, 2002.

[6] K. Allaf, N. Louka, A. Habba, Z. Maache, S.A. Rezzoug. Diverse thermal, pressure and vacuum treatment for e.g. moist foods, cosmetics, chemical and pharmaceutical products. Publication No.: FR2774913; Date of issue: 20/08/ 1999, 1999.

[7] S. Mounir, K. Allaf. Proceedings of AFSIA, Lyon (France), 2009.

[8] S. Mounir, K. Allaf. J. Drying Technol., 2008; 26(4), 452-463. DOI:10.1080/07373930801929334.

[9] K. Allaf. Transfer phenomena and industrial application, The Lebanese University, Faculty of Science, 1982.

[10] A.S. Mujundar. Handbook of Industrial Drying, 3rd edn. (Eds.: CRC), Taylor \& Francis Group Press, 2006.

[11] J. Crank. The mathematics of diffusion, Clarendon Press, Oxford, England, 1975.

[12] Z. Pakowski, A.S. Mujumdar. In Handbook of Industrial Drying, 3rd edn. (Eds.: CRC), Taylor \& Francis Group Press, 2006.

[13] M.A. Tutuncu, T.P. Labuza. J. Food Eng., 1996; 30, 433-447.

[14] J.A. Larrauri, P. Ruperez, B. Borroto, F. Saura-Calixto. Lebensm.-Wiss.Technol., 1996; 29, 729-733. 


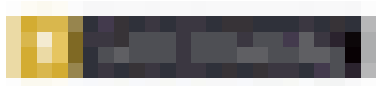

1月+1
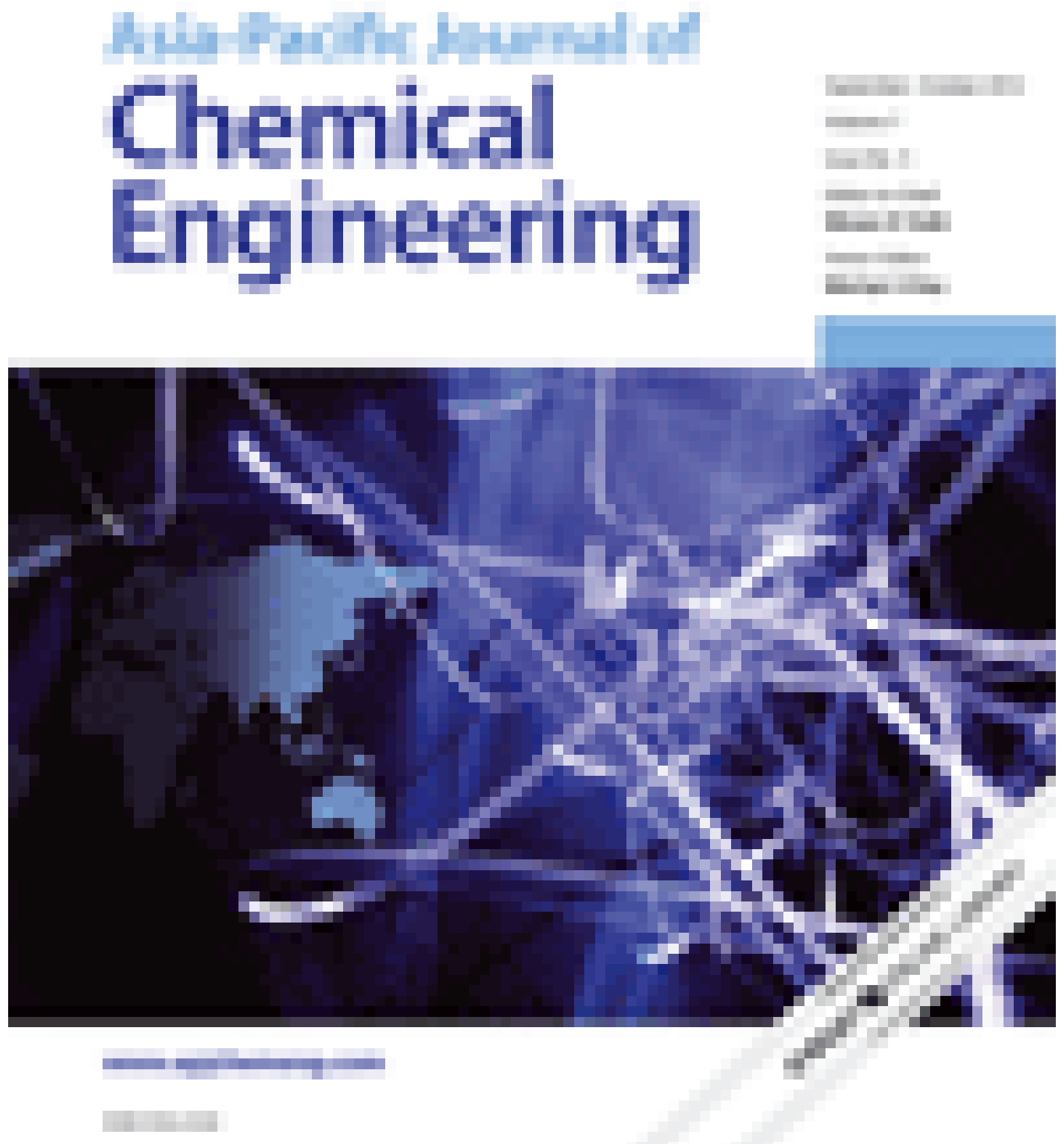


\section{Microservices Architecture}

Free White Paper

\section{Asia-Pacific Journal of Chemical Engineering}

COUNTRY

United States

Universities and research institutions in United States

PUBLICATION TYPE

Journals
SUBJECT AREA AND CATEGORY

Chemical Engineering

Chemical Engineering (miscellaneous)

Energy

Renewable Energy, Sustainability and the Environment

Environmental Science

Waste Management and Disposal

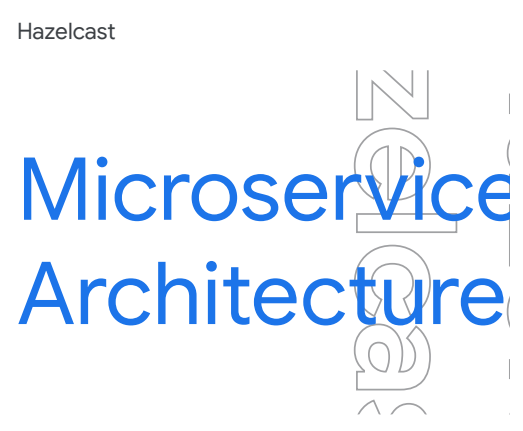

Open
PUBLISHER

Wiley-

Blackwell 


\section{SCI Journal}

Impact Factor Database

\section{Asia-Pacific Journal Of Chemical Engineering Basic Journal Info \\ Country \\ United States (https://www.scijournal.org/country/united-states) \\ Journal ISSN: 19322143, 19322135}

Publisher: Wiley-Blackwell (https://www.scijournal.org/publishers/wiley-blackwell)

History: 1993-1995, 2006-ongoing

Journal Hompage: Link (http://www.wiley.com/bw/journal.asp?ref=1743-7555)

Note:

\section{Research Categories}

Chemical Engineering (https://www.scijournal.org/categories/chemical-engineering)

Energy (https://www.scijournal.org/categories/energy)

Environmental Science (https://www.scijournal.org/categories/environmental-science) 


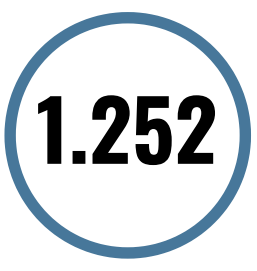

3-year Impact Factor

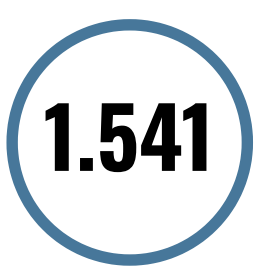

4-year

Impact Factor

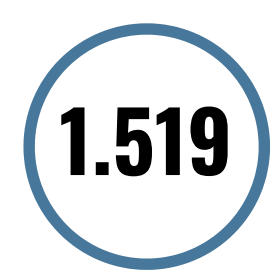

\section{Scope/Description:}

The Asia-Pacific Journal of Clinical Oncology is a multidisciplinary journal of oncology that aims to be a forum for facilitating collaboration and exchanging information on what is happening in different countries of the Asia Pacific region in relation to cancer treatment and care. The Journal publishes pre-clinical studies, translational research, clinical trials and epidemiological studies, describing new findings of clinical significance. Clinical studies, particularly prospectively designed clinical trials, are encouraged.

\section{Asia-Pacific Journal Of Chemical Engineering}


JOURNAL IMPACT FACTOR DETAILS

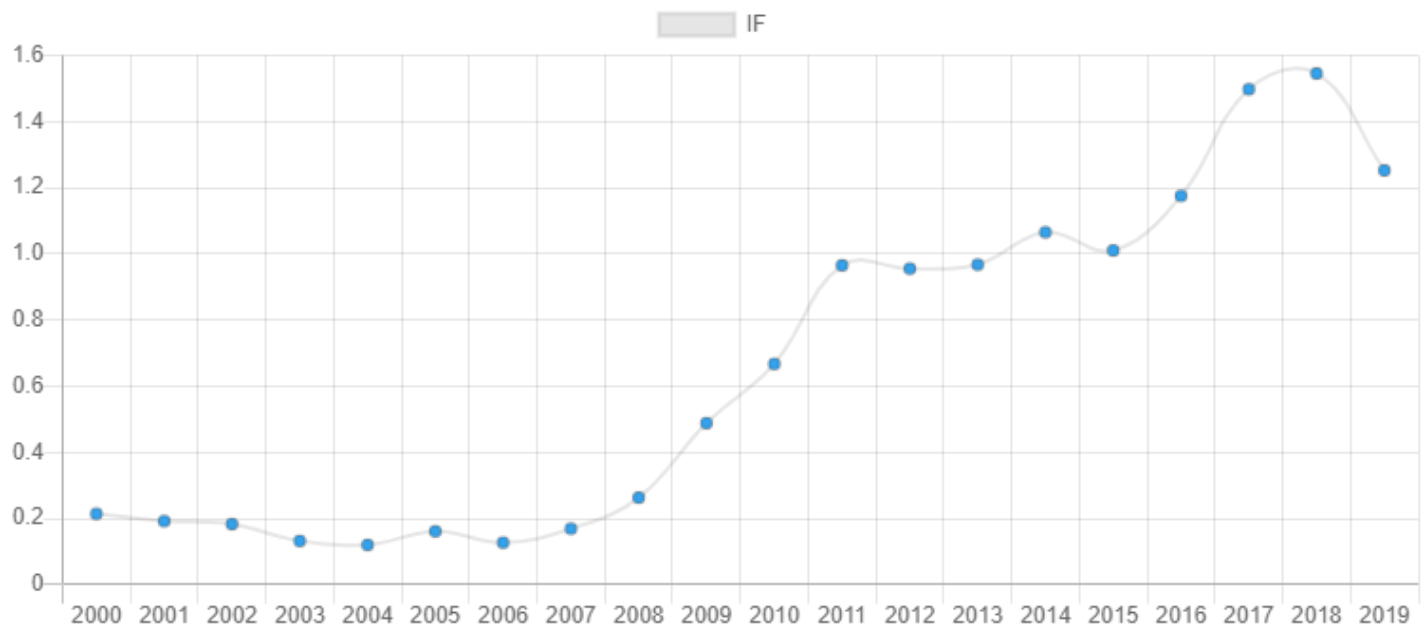

Note: impact factor data for reference only

\section{Asia-Pacific Journal Of Chemical Engineering}

3-year Impact Factor Trend

JOURNAL IMPACT FACTOR DETAILS

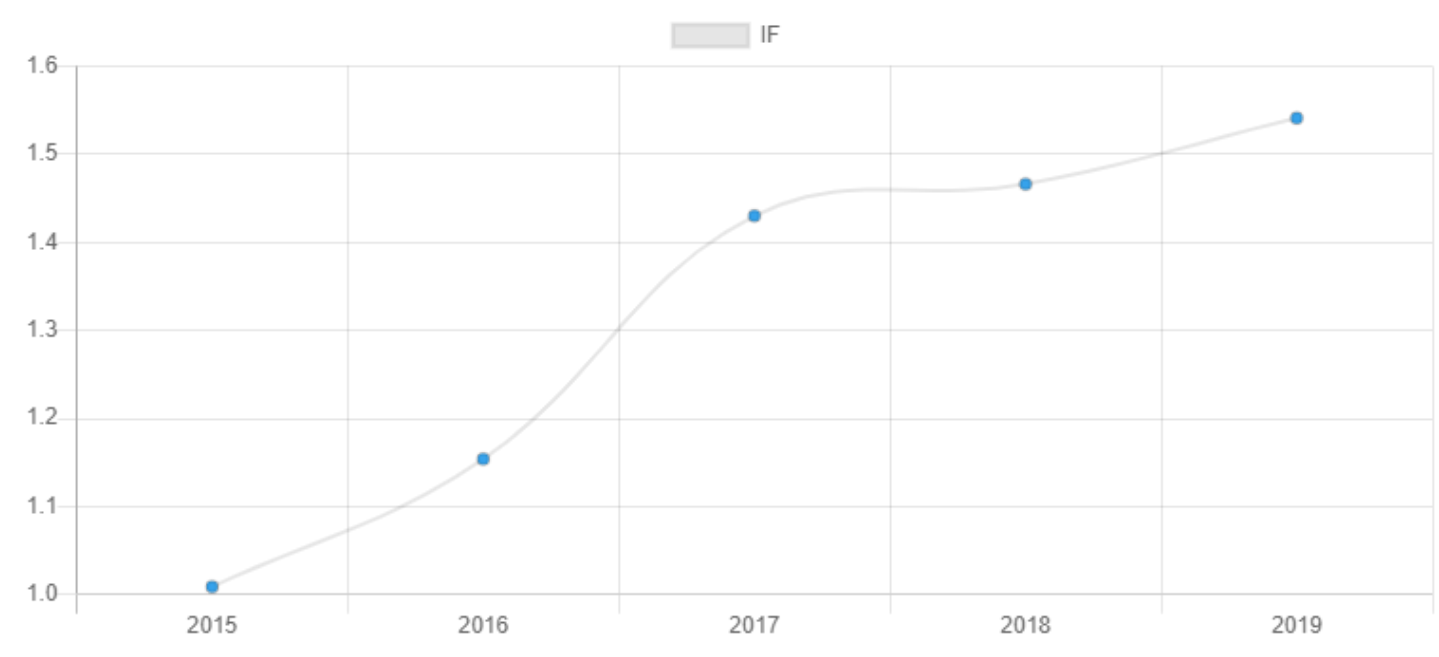




\section{Asia-Pacific Journal Of Chemical Engineering}

\section{4-year Impact Factor Trend}

JOURNAL IMPACT FACTOR DETAILS

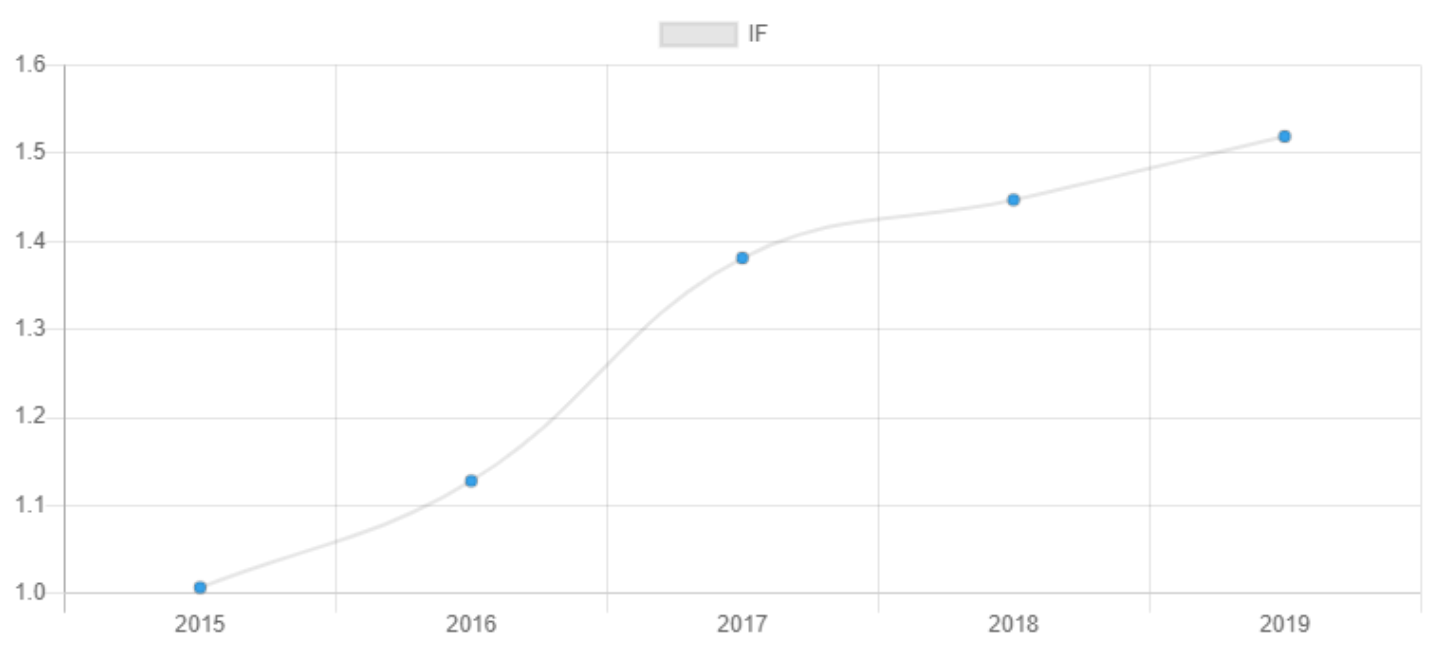

Note: impact factor data for reference only

\section{Impact Factor}

The impact factor (IF) or journal impact factor (JIF) of an academic journal is a scientometric factor based on the yearly average number of citations on articles published by a particular journal in the last two years. In other words, the impact factor of 2020 is the average of the number of cited publications divided by the citable publications of a journal. A journal impact factor is frequently used as a proxy for 
Find out more: What is a good impact factor? (https://www.scijournal.org/articles/good-impact-factor)

And check out: How to get published in a top science journal? (https://www.scijournal.org/articles/category/career-success)

\title{
Asia-Pacific Journal Of Chemical Engineering
}

\author{
Impact Factor History
}

2019 Impact Factor

2018 Impact Factor

2017 Impact Factor 1.497

2016 Impact Factor 1.175

2015 Impact Factor 1.010

2014 Impact Factor 1.065

2013 Impact Factor 0.967

2012 Impact Factor 0.955

2011 Impact Factor 0.965

2010 Impact Factor 0.667

2009 Impact Factor 0.488

2008 Impact Factor

2007 Impact Factor 0.169

2006 Impact Factor 0.127

2005 Impact Factor 0.161

2004 Impact Factor 0.120

2003 Impact Factor 0.132

2002 Impact Factor 0.183

2001 Impact Factor 0.192

2000 Impact Factor

Note: impact factor data for reference only

See what other people are reading

DISCOVER 


\title{
Other Journal Impact Indicator
}

Any journal impact factor or scientometric indicator alone will not give you the full picture of a science journal. That's why every year, scholars review current metrics to improve upon them and sometimes come up with new ones. There are also other factors to sider for example, H-Index, Self-Citation Ratio, SJR (SCImago Journal Rank Indicator) and SNIP (Source Normalized Impact per Paper). Researchers may also consider the practical aspect of a journal such as publication fees, acceptance rate, review speed.

(Read More)

\section{Asia-Pacific Journal Of Chemical Engineering}

\author{
H-Index
}

The h-index is an author-level metric that attempts to measure both the productivity and citation impact of the publications of a scientist or scholar. The index is based on the set of the scientist's most cited papers and the number of citations that they have received in other publications

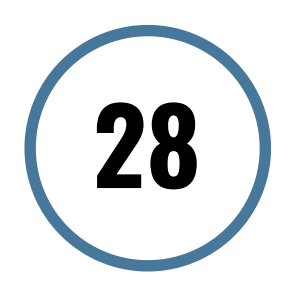

\section{Asia-Pacific Journal Of Chemical Engineering}

SCImago Journal Rank (SJR)

SCImago Journal Rank (SJR indicator) is a measure of scientific influence of scholarly journals that accounts for both the number of citations received by a journal and the importance or prestige of the journals where such citations come from. 
scijournal.org is a platform dedicated to making the search and use of impact factors of science journals easier.

Copyright 2012-2020 scijournal.org 


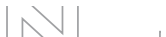 \\ Microservices Architecture
}

Hazelcast

Open

SCOPE

Asia-Pacific Journal of Chemical Engineering is aimed at capturing current developments and initiatives in chemical engineering $\mathrm{r}$ specialised areas. Publishing six issues each year, the journal showcases innovative technological developments, providing an opI technology transfer and collaboration. Asia-Pacific Journal of Chemical Engineering will focus particular attention on the key area: Application (separation, polymer, catalysis, nanotechnology, electrochemistry, nuclear technology); Energy and Environmental Tecl for energy storage and conversion, coal gasification, gas liquefaction, air pollution control, water treatment, waste utilization and $\mathrm{n}$ nuclear waste remediation); and Biochemical Engineering (including targeted drug delivery applications).

\section{Microservices Architecture}

\author{
Free White Paper
}

$\hat{\imath}$ Quartiles 


\section{Microservices Architecture}

Hazelcast
2

Canadian Journal of Chemical Engineering USA

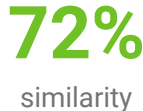

3 International Journal of Chemical Reactor DEU

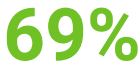

4

Reviews in $\mathrm{C}$ Engineering DEU

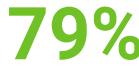

similarity similarity

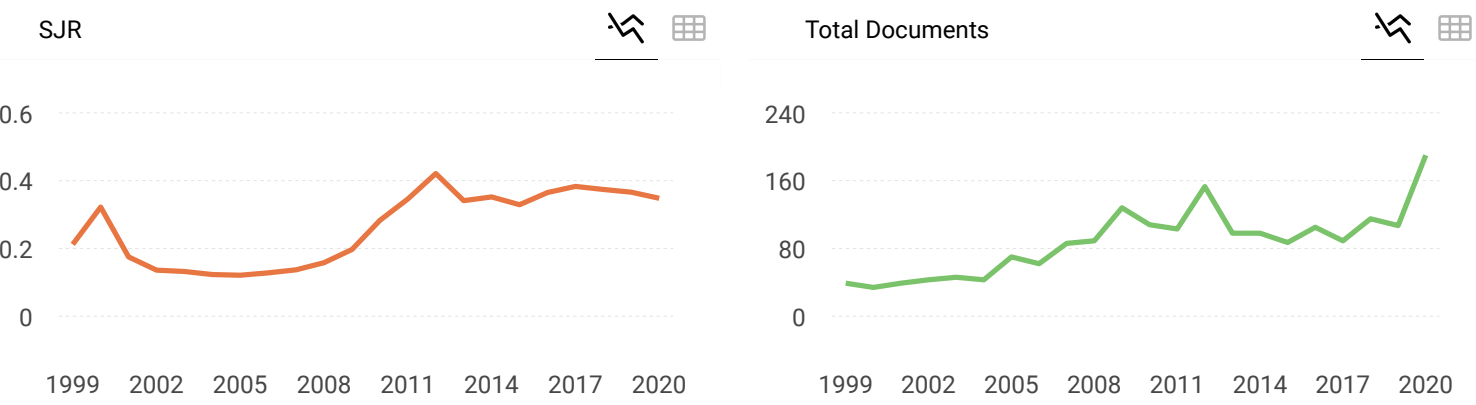

Total Cites Self-Cites 梌囲

600

300

$\begin{array}{llllllll}1999 & 2002 & 2005 & 2008 & 2011 & 2014 & 2017 & 2020\end{array}$

External Cites per Doc Cites per Doc 糸困

2.4

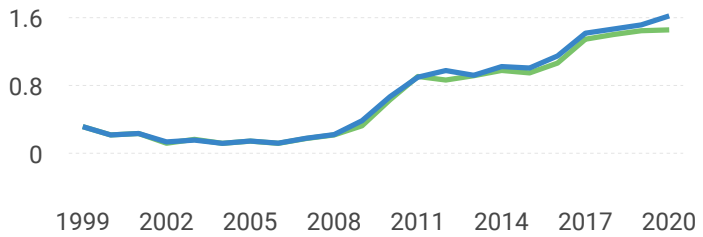

Citations per document

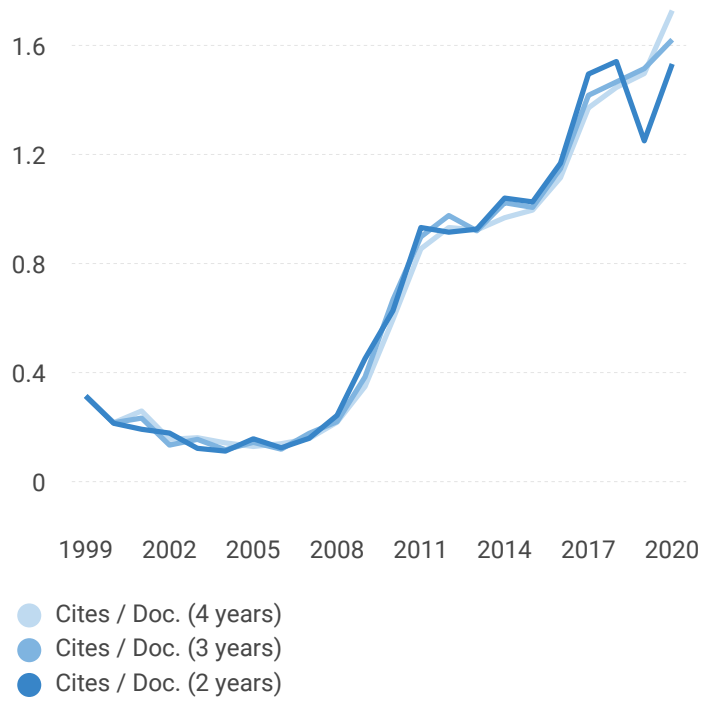

$\%$ International Collaboration 命困 Citable documents Non-citable documents 梌囲 
40

20

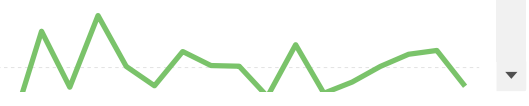

Cited documents

Uncited documents

梌困

400

200

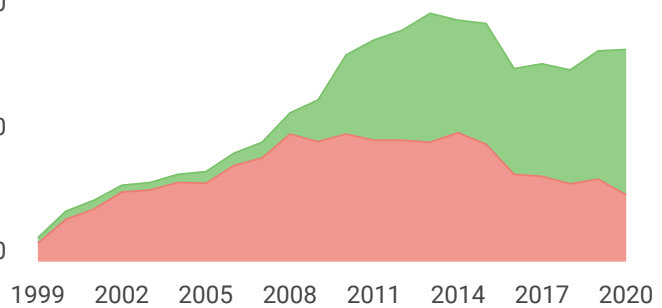

400

200

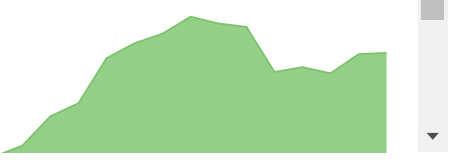

$\leftarrow$ Show this widget in your own website

Asia-Pacific Journal of Chemical Engineering

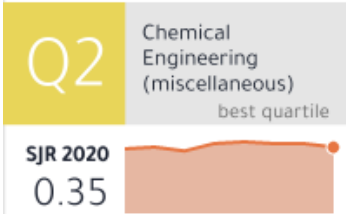

powered by scimagojr.com
Just copy the code below and paste within your html code:

| <a href="https://www.scimas
G SCImago Graphica

Explore, visually communicate and make sense of data with our new free tool.

Get it

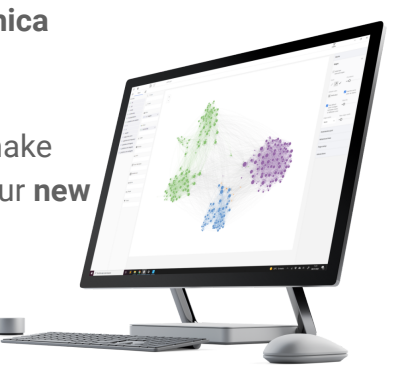

\section{Microservices Architecture}

Free White Paper

Hazelcast

Metrics based on Scopus $\AA$ data as of April 2021

\section{Leave a comment}

Name

Email

(will not be published)
Microservices Architecture

Free White Paper Hazelcast 


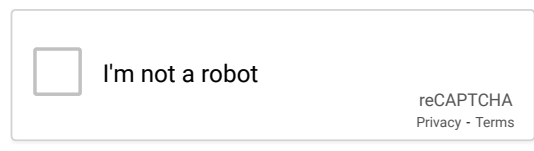

Submit

The users of Scimago Journal \& Country Rank have the possibility to dialogue through comments linked to a specific journal. The purpose is to have a forum in which general doubts about the processes of publication in the journal, experiences and other issues derived from the publication of papers are resolved. For topics on particular articles, maintain the dialogue through the usual channels with your editor.

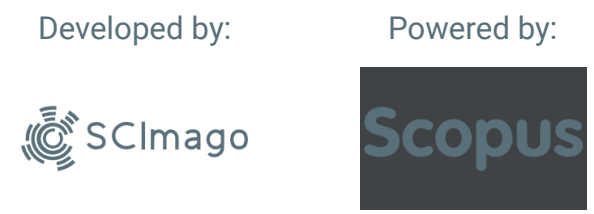

Follow us on @ScimagoJR

Scimago Lab, Copyright 2007-2020. Data Source: Scopus ${ }^{\circledR}$

EST MODUS IN REBUS

Microservices Architecture

Free White Paper Hazelcast 


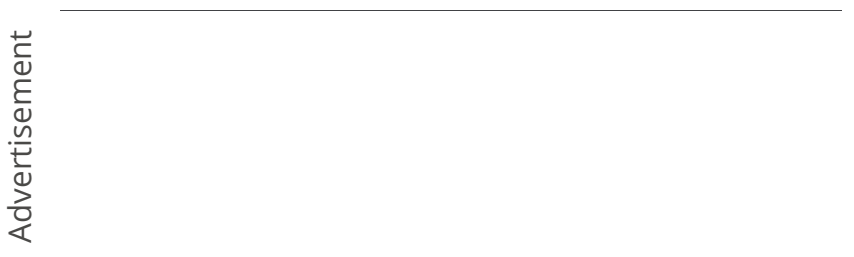

\section{14 Asia-Pacific Journal of University Chemical Engineering}

\section{Editorial Board}

\section{EDITOR-IN-CHIEF \\ Moses O. Tadé}

Faculty of Science and Engineering

Curtin University

GPO Box U1987, Perth 6845

Western Australia

Australia

Phone: (08) 9266-7702

Fax: (08) 9266-2681

Email: M.O.Tade@curtin.edu.au

\section{EDITOR}

\section{Hong Mei Yao}

Western Australian School of Mines: Minerals, Energy and Chemical Engineering

Curtin University

GPO Box U1987, Perth 6845

Western Australia

Australia

Phone: (08) 9266-3677

Fax: (08) 9266-2681

Email: H.Yao@curtin.edu.au

\section{ASSOCIATE EDITORS}

\section{Ali Abbas}

School of Chemical and Biological Engineeing The University of Sydney

Sydney

Australia

\section{FOUNDING SENIOR EDITOR}

Martyn S. Ray

Department of Chemical Engineering

Curtin University

GPO Box U1987, Perth 6845

Western Australia

Australia

\section{$\square$ Angelo Basile}

Senior Researcher

Institute of Membrane Technology

Italian National Research Council

Rende

Italy 
Jasmina Casals-Terré

Department of Mechanical Engineering Universitat Politècnica de Catalunya Spain

\section{Nina Fechler}

Department of Colloid Chemistry

Max Planck Institute of Colloids and Interfaces

Germany

\section{Gianluca Coccia}

Department of Industrial Engineering and Mathematical Sciences

Marche Polytechnic University

Italy

\section{Guntae Kim}

School of Energy and Chemical Engineering Ulsan National Institute of Science and Technology

Ulsan

Republic of Korea

\section{Osvaldo Gozá León}

Faculty of Chemical Engineering Technological University of Havana "José Antonio Echeverría", CUJAE Cuba

\section{Iqbal M. Mujtaba}

School of Engineering University of Bradford UK

University of Surrey

UK

\section{Zoltan K. Nagy}

School of Chemical Engineering

Purdue University

West Lafayette

USA

\section{高 Jaka Sunarso}

Faculty of Engineering, Computing and Science Swinburne University of Technology Sarawak Campus

Malaysia

\section{Yu-Chun Tian}

School of Electrical Engineering and Computer Science

Queensland University of Technology

Brisbane 4001 QLD

Australia

\section{Junwang Tang}

Department of Chemical Engineering University College London

UK

\section{Ming-Hou Xu}

State Key Laboratory of Coal Combustion Huazhong University of Science \& Technology Wuhan, Hubei 430074

P.R. China 


\section{Brent Young}

Department of Chemical \& Materials

Engineering

University of Auckland

New Zealand
John Zhu

School of Chemical Engineering

University of Queensland

Brisbane 4072 QLD

Australia

\section{EDITORIAL ADVISORY BOARD}

\section{Mohd Azlan Bin Hussain}

Department of Chemical Engineering

Faculty of Engineering

University Malaya

Kuala Lumpur 50603

Malaysia

\section{Su Max Lu}

President and Vice Chancellor

University of Surrey

UK
Wan-Qin Jin

College of Chemistry and Chemical Engineering Nanjing University of Technology, Nanjing P. R. China

\section{* Arun S. Mujumdar}

Mining and Materials Engineering

McGill University

Montreal, Canada

and

Chemical and Biochemical Engineering

Western University

London, Ontario, Canada

\section{Gade P. Rangaiah}

Department of Chemical \& Biomolecular Engineering

National University of Singapore

Singapore

\section{Shantanu Roy}

Department of Chemical Engineering Indian Institute of Technology-Delhi

Hauz Khas, New Delhi 11006

India

\section{$\square+\downarrow$ w (Bill) Y. Svrcek}

Department of Chemical \& Petroleum

Engineering

University of Calgary

Calgary

Alberta

Canada T2E 2R2

Tools 
a Submit an Article

A Browse free sample issue

- Get content alerts

- Subscribe to this journal

\section{Published in partnership with}

\section{Curtin University}

More from this journal

Special Issue on Microfluidic Technology - Call for Papers

News

Practical Advice for Authors

Keyword Tag Cloud

\section{D | VER S | TY in Research Jobs}

Please contact us to see your job listed here

Assistant Professor of Digital Chemistry

Zurich, Switzerland $\mid$ negotiable

The Department of Chemistry and Applied Biosciences at

EHHzürich ETH Zürich invites applications for the above-mentioned position.

Employer: ETH Zurich

Apply for this job

\section{Senior Applications Engineer}

Bridgewater, NJ, United States | Competitive

HENKEL IS FOR THOSE WHO STEP UP. DO YOU? At Henkel, you can make a difference and craft your career. That's why you own your projects and take full...

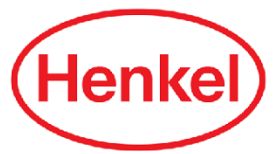

Apply for this job

Sport and Fashion Engineer TCS Field in central Java Tangerang, Indonesia | Competitive

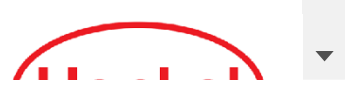




\author{
Privacy Policy \\ Terms of Use \\ Cookies \\ Accessibility \\ Help \& Support \\ Contact Us \\ Training and Support \\ DMCA \& Reporting Piracy \\ Opportunities \\ Subscription Agents \\ Advertisers \& Corporate Partners \\ Connect with Wiley \\ The Wiley Network \\ Wiley Press Room
}

Copyright (c) 1999-2021 John Wiley \& Sons, Inc. All rights reserved 


\section{Volume 7, Issue 5}

\section{Pages: 633-794}

September/October 2012

〈Previous Issue | Next Issue >

$: \equiv$ GOTO SECTION

"Export Citation(s)

\section{Guest editorial}

4th Symposium on advanced control of industrial processes (Adconip)

Lei Xie, Furong Gao, Biao Huang

Pages: 633-634 | First Published: 04 October 2012

Full text | PDF | Request permissions

\section{Special theme research articles}

Soft sensing and optimization of pesticide waste incinerator

Zhengbing Yan, Xinggao Liu

Pages: 635-641 | First Published: 15 February 2012

Abstract | Full text | PDF | References | Request permissions

Adaptive fault-tolerant control based on hybrid redundancy

Masanori Takahashi, Taro Takagi 
Pages: 642-650 | First Published: 16 March 2012

Abstract | Full text | PDF | References | Request permissions

Information system integration model of manufacturing enterprise based on object process methodology and its application

Qinghong Shen, Hongye Su

Pages: 651-659 | First Published: 07 February 2012

Abstract | Full text | PDF | References | Request permissions

Application of the parallel adaptive genetic simulated annealing algorithm for the synthesis of heat exchanger networks

Chao Zhao, Qiaoling Xu, Aimin An

Pages: 660-669 | First Published: 24 February 2012

Abstract | Full text | PDF | References | Request permissions

\section{Leak detection of gas pipelines based on Wigner distribution}

Shouchao Zhai, Fan Yang, Hongying Yang, Hao Ye, Guizeng Wang

Pages: 670-677 | First Published: 18 April 2012

Abstract | Full text | PDF | References | Request permissions

On-line estimation of glucose and biomass concentration in batch fermentation process using particle filter with constraint

Zhonggai Zhao, Xinguang Shao, Biao Huang, Fei Liu

Pages: 678-686 | First Published: 01 March 2012

Abstract | Full text | PDF | References | Request permissions

\section{Research articles}


Experimental study of two-phase flow instability of vertical parallel rifled tube with different sizes at low-mass flow rate

Zhian Deng, Yushan Luo, Haijun Wang, Tingkuan Chen

Pages: 687-697 | First Published: 20 July 2011

Abstract | Full text | PDF | References | Request permissions

The production of methyl esters from waste frying oil by microwave method İsa Rahmanlar, Sevil Yücel, Didem Özçimen

Pages: 698-704 | First Published: 27 July 2011

Abstract | Full text | PDF | References | Request permissions

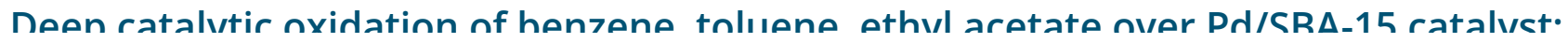

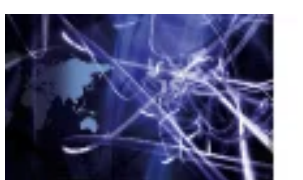

Asia-Pacific Journal of Curtin University

Chemical Engineering

Effect of pre-oxidation of $\mathrm{Fe}_{3} \mathrm{Al}$ on its corrosion resistance in sulfur and chlorine contaminated syngas

Alexander Y. Ilyushechkin, Michael D. Dolan, Keith G. McLennan, Sunil D. Sharma

Pages: 716-725 | First Published: 16 August 2011

Abstract | Full text | PDF | References | Request permissions

The dehydration kinetics, physical properties and nutritional content of banana textured by instantaneous controlled pressure drop

Puguh Setyopratomo, Akbarningrum Fatmawati, Putu Doddy Sutrisna, Emma Savitri, Karim Allaf Pages: 726-732 | First Published: 23 August 2011

Abstract | Full text | PDF | References | Request permissions

Derivation of critical and optimal operating conditions for a semibatch reactor under parametric uncertainty based on failure probability indices

Gheorghe Maria, Anca Dan

Pages: 733-746 | First Published: 23 September 2011 
Abstract | Full text | PDF | References | Request permissions

Preparation and characterization of polyimide and polyethersulfone blend membrane for gas separation

S. S. Madaeni, R. Mohammadi Nooripour, V. Vatanpour

Pages: 747-754 | First Published: 23 August 2011

Abstract | Full text | PDF | References | Request permissions

Temperature evaluated by ultrasonic technique during mixing process

Chin-Chi Cheng, Chi-Huang Lu

Pages: 755-760 | First Published: 23 September 2011

Abstract | Full text | PDF | References | Request permissions

Biosorption of Reactive Red 198 from an aqueous solution using Acalypha indica

N. Praveena, P. Saravanan, M. Dharmendira Kumar, N. Nagendra Gandhi, S. Renganathan

Pages: 761-768 | First Published: 06 September 2011

Abstract | Full text | PDF | References | Request permissions

Biomass char as a fuel for internal combustion engines

Gary K Ellem, Cara J Mulligan

Pages: 769-776 | First Published: 18 November 2011

Abstract | Full text | PDF | References | Request permissions

Analysis of operation conditions for a pilot-scale supercritical $\mathrm{CO}_{2}$ extraction of diterpenoid from Pteris semipinnata $\mathrm{L}$.

Yingnian Lu, Baozhang Zhu, Kefeng Wu, Zhanping Gou, Li Li, George G Chen, Liao Cui, Nianci Liang Pages: 777-782 | First Published: 23 September 2011

Abstract | Full text | PDF | References | Request permissions

Parameter estimation of industrial PET reactor using multi-objective kernel density estimation of distribution algorithm

Na Luo, Feng Qian 
Pages: 783-794 | First Published: 18 November 2011

Abstract | Full text | PDF | References | Request permissions

\section{Tools}

(2) Submit an Article

B Browse free sample issue

- Get content alerts

Subscribe to this journal

Published in partnership with

\section{Curtin University}

More from this journal

Special Issue on Microfluidic Technology - Call for Papers

News

Practical Advice for Authors

Keyword Tag Cloud 


\title{
DIVERSITY \\ in Research Jobs
}

Please contact us to see your job listed here

\section{Chemistry Instructor}

Illinois Medical District, IL

Chamberlain University has an immediate need for part-time faculty to teach Chemistry in our Bachelors of Science in Nursing program at our Chicago...

Employer: Chamberlain University

Apply for this job

\section{Open-Rank Assistant/Associate/Professor in Nuclear and Radiological and Medical Physics Program}

Atlanta, GA

Job Title: Open-Rank Assistant/Associate/Professor in Nuclear and Radiological and Medical Physics Program Location: Atlanta, Georgia Regular/Tempo...

Employer: Georgia Institute of Technology

Apply for this job

\section{Sr. Biologics Engineer I, MS\&T (CPV)}

Morris Plains, NJ

\section{About Wiley Online Library \\ Privacy Policy \\ Terms of Use \\ Cookies \\ Accessibility \\ Publishing Policies \\ Help \& Support}

Contact Us

Training and Support

DMCA \& Reporting Piracy

\section{Opportunities}

\section{Subscription Agents}

Advertisers \& Corporate Partners

\section{Connect with Wiley}

\author{
The Wiley Network \\ Wiley Press Room
}


Copyright (c) 1999-2021 John Wiley \& Sons, Inc. All rights reserved 